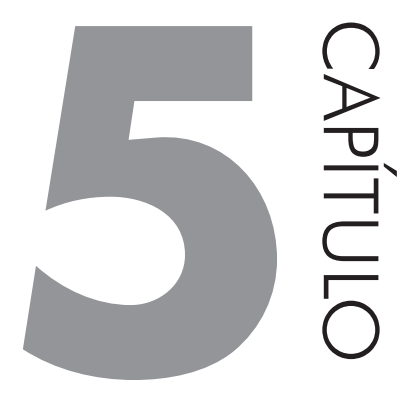

\title{
ASPECTOS INSTITUCIONAIS E REGULATÓRIOS DA ÁGUA DE LASTRO
}

\section{NEWTON NARCISO PEREIRA E HERNANI BRINATI}

\subsection{AÇÕES INTERNACIONAIS}

As ações internacionais para inibição do problema da bioinvasão por meio da água de lastro podem ser divididas em duas frentes. A primeira é a atuação da Organização Marítima Internacional - IMO na regulação e estabelecimento de regras de operação para os navios e portos e as ações dos próprios membros da IMO. A segunda refere-se aos esforços de várias nações para estabelecer regras para controlar o despejo da água de lastro em seu território.

\subsubsection{Atuação da IMO}

A IMO tem dado importância para as implicações das introduções de espécies exóticas e organismos aquáticos oriundos de água de lastro há três décadas. Em 1973, durante a Conferência Internacional de Poluição Marítima foi aprovada a Resolução 18 de Pesquisa dos Efeitos da Descarga de Água de Lastro contendo Bactérias Epidêmicas, que passou para a IMO, a responsabilidade de elaborar medidas de controle, chamando a atenção mundial para o transporte nos tanques de lastros dos navios de espécies patogênicas em torno do mundo. 
EMMANUELA (2007) apresenta um levantamento cronológico dos principais marcos alcançados para implementação de uma legislação internacional dedicada ao tratamento da questão da água de lastro, conforme descrito a seguir.

O primeiro esforço mundial efetivo de controlar a dispersão de espécies alienígenas ocorreu em 1982, com a criação da Convenção das Nações Unidas sobre o Direito do Mar - United Nations Convention on the Law of the Sea - UNCLOS. A parte XII da UNCLOS impunha uma série de obrigações para os países membros, relevantes para o controle de espécies invasoras alienígenas. O Parágrafo $1^{\circ}$ do Artigo 196 da UNCLOS prevê que "os Estados deverão tomar todas as medidas necessárias para prevenir, reduzir e controlar a poluição do ambiente marinho resultante do uso de tecnologias sob a sua jurisdição ou controle, ou a introdução intencional ou acidental de espécies, sejam elas exóticas ou novas, em uma determinada parte do ambiente marinho, que possa causar mudanças significativas e prejudiciais ao mesmo".

Em 1990, o Comitê de Proteção Ambiente Marinho (MEPC) formou um grupo de trabalho para considerar pesquisas, informações e soluções propostas por Estados Membros da IMO e por Organizações Não Governamentais. A conclusão do grupo de trabalho foi à criação de um relatório contendo diretrizes para direcionar o problema da bioinvasão marinha por meio da água de lastro.

Em 1991, foram estabelecidas as primeiras diretrizes não obrigatórias pelo MEPC. As diretrizes indicaram para os administradores e as autoridades do Porto informações e procedimentos para minimizar o risco de introdução de espécies aquáticas indesejadas contidas na água de lastro e no sedimento no fundo dos tanques de lastro.

No início de 1997, antes da revisão das diretrizes, o Comitê de Segurança Marítima - MSC e o MEPC aprovaram diretrizes contendo os aspectos de segurança, sugerindo a troca da água de lastro no oceano. Nestas diretrizes, também foram apontadas as medidas de segurança que seriam necessárias para considerar o problema de baixa pressão nos tanques de lastro, e os requisitos operacionais para navegação em condições ambientais adversas. Em março de 1997, a Assembleia Geral da IMO adotou a Resolução A. 868 (20).

A IMO, em conjunto com a Global Environment Facility e o United Nations Development Programme, desenvolveram, em 2000, o programa Removal of Barriers to the Effective Implementation of Ballast Water Control and Management Measures in Developing Countries, mais conhecido como Global Ballast Water Management Programme ou apenas Globallast. O Globallast teve como objetivo ajudar países em desenvolvimento a lidar com o problema da água de lastro, implementando os procedimentos de controle sugeridos pela IMO (PEREIRA e BRINATI 2008; PEREIRA \& CONTI, 2008). 
O projeto visava reduzir a transferência de espécies marinhas alienígenas que tinha como vetor a água de lastro dos navios (PEREIRA e BRINATI, 2008). Foram selecionadas seis regiões de países em desenvolvimento: Sepetiba - Brasil, Dalian - China, Bombaim - Índia, Ilha Kharg - Irã, Saldanha - África do Sul e Odessa - Ucrânia. Dentre as várias premissas estabelecidas pelo programa, a principal delas era estabelecer parâmetros para avaliação do risco de água de lastro e um levantamento da biota dos portos.

O programa piloto permitiu que os países participantes recebessem assistência técnica, capacitação e reforço institucional. Os estudos desenvolvidos estão servindo como demonstração das dificuldades e das experiências de sucesso na gestão do problema (IMO, 2003).

A principal contribuição do programa Globallast foi o estabelecimento de uma metodologia para comparação do risco de contaminação entre o porto doador e o receptor. Esta análise é baseada na comparação de dados dos portos, na porcentagem do número de navios que chegam de um mesmo porto, e da porcentagem do volume de água que chega de um determinado porto (HENRIQUE, 2006). Assim, foram determinados os seguintes elementos de comparação:

- C-1 Coeficiente de risco de frequência de Visitas de Inoculação;

- C-2 Coeficiente de Risco de Volume de Inoculação;

- C-3 Coeficiente de Similaridade Ambiental;

- C-4 Coeficiente de Espécies de Risco do Porto Doador.

Além destes coeficientes, dois fatores de redução foram determinados:

- R-1 Fator de correção de risco em função do volume máximo por tanque descarregado;

- R-2 Fator de redução de risco de armazenamento.

Com estes fatores mapeados, pode-se utilizar as formulações disponíveis no relatório da IMO e calcular o coeficiente global de risco, para classificar o grau de risco, segundo a origem da água de lastro. Para determinar estes parâmetros foram padronizados métodos aplicados nos seis países pilotos que participaram do programa.

Deste modo, foi criado um banco de dados reunindo as informações necessárias para determinação dos coeficientes, bem como a utilização de softwares que permitiram apresentar mapas distintos com os dados de cada bioregião (LEAL NETO, 2007). A primeira parte do programa se encerrou em 2003. Maiores informações da aplicação deste procedimento podem ser encontradas no site do Globallast - Http://globallast.imo.org.

Ao término do Globallast, o MEPC consolidou uma proposta final encaminhada para a $49^{\text {a }}$ Convenção da IMO, em julho de 2003, enviada também para a 
conferência diplomática, em fevereiro de 2004, com objetivo de formalizar as diretrizes já aprovadas pelo conselho da IMO. As diretrizes foram finalmente aprovadas em consenso numa conferência diplomática na sede da IMO, em Londres, em 2004, após 14 anos de complexas negociações entre a IMO, países membros, armadores e ONG's dando origem à Convenção Internacional para Controle e Gerenciamento de Água de Lastro de Navios e Sedimentos - BWMC.

\subsubsection{A BWMC}

$\mathrm{Na}$ conferência realizada em Londres de 2004, que deu origem à $B W M C$ haviam 74 Estados Membros, além de várias organizações não governamentais. A BWMC entrará em vigor 12 meses após a data em que não menos do que 30 Estados membros, cujas frotas mercantes combinadas constituam não menos que $35 \%$ da arqueação bruta da frota mercante mundial, tenham assinado a mesma sem reservas quanto a sua ratificação, aceitação ou aprovação.

Inicialmente, oito países sinalizaram ter intenção de ratificar a BWMC em junho 2005, destes, oficialmente, apenas seis assinaram o acordo representando $0.62 \%$ da tonelagem mundial, sendo Argentina, Austrália, Finlândia, Maldivas, Holanda, Espanha, Republica Árabe Síria e Brasil. Até outubro de 2009 apenas 18 países ratificaram ou aderiram à BWMC representando aproximadamente $15,36 \%$ da arqueação bruta mundial. Em 30 de junho de 2009, a Comissão de Cidadania e Justiça - CCJ do Brasil apresentou parecer favorável para que o Brasil ratifique a BWMC, encaminhando assim o documento para ser votado no congresso (ÁGUA DE LASTRO BRASIL, 2009). Em maio de 2010 o Brasil ratificou a BWMC.

Ao longo dos anos diversos países foram ratificando a BWMC, porém com pouca expressividade em termos de frota marítima. Isso fez com que fosse necessários 12 anos entre a criação da BWMC até sua efetiva regulamentação.

Assim, até setembro de 2017, um total de 63 países ratificaram a BWMC e totalizaram $68,51 \%$ da tonelagem bruta mundial que permitiu sua entrada em vigor.

\section{Principais requisitos da BWMC}

Dentre os principais requisitos estabelecidos na BWMC, podem-se destacar os seguintes:

- Todo navio deve ter a bordo um plano de gestão de água de lastro. Gestão de Água de Lastro significa processos mecânicos, físicos, químicos e biológicos, sejam individualmente ou em combinação, para remover, tornar inofensiva ou evitar a captação ou descarga de Organismos Aquáticos Nocivos e Agentes Patogênicos encontrados na Água de Lastro e Sedimentos nela contidos. Basicamente, cada navio deverá ter a bordo um 
Livro Registro da Água de Lastro que poderá ser um sistema de registro eletrônico ou poderá ser integrado a outro livro ou sistema de registros e que deverá, pelo menos, conter as informações especificadas do local onde captou e despejou a água e o volume dos tanques, bem como a posição geográfica.

- Para o navio construído antes de 2009: com uma capacidade de Água de Lastro entre 1.500 e 5.000 metros cúbicos, inclusive, deverá efetuar a Gestão de Água de Lastro que pelo menos siga a norma descrita na Regra D-1 ou Regra D-2 até 2014, a partir de quando deverá obedecer pelo menos a norma descrita na Regra D-2. A Regra D2 estabelece a eficiência do tratamento da água de lastro em termos de redução de organismos presentes na água.

- Navio com uma capacidade de água de lastro menor que 1.500 ou maior que 5.000 metros cúbicos deverá efetuar a Gestão de Água de Lastro que pelo menos siga a norma descrita na Regra D-1 ou Regra D-2 até 2016.

- Um navio construído em 2009 ou a partir desta data com uma Capacidade de Água de Lastro menor que 5.000 metros cúbicos deverá efetuar a Gestão de Água de Lastro que pelo menos obedeça a norma descrita na Regra D-2.

- Um navio construído entre 2009 e 2012 com uma Capacidade de Água de Lastro de 5.000 metros cúbicos ou mais deverá efetuar a Gestão de Água de Lastro.

- Um navio construído em 2012 ou depois deste ano com uma Capacidade de Água de Lastro de 5000 metros cúbicos ou mais deverá administrar a Gestão de Água de Lastro que pelo menos obedeça à norma descrita na Regra D-2.

O navio deve cumprir a troca da água de lastro considerando:

- Sempre que possível, deve realizar a troca da Água de Lastro a pelo menos 200 milhas náuticas da terra mais próxima e em águas com pelo menos 200 metros de profundidade levando em conta as Diretrizes desenvolvidas pela Organização.

- Nos casos em que o navio não puder realizar troca da Água de Lastro, deve buscar realizá-la o mais distante possível da terra mais próxima, e em todos os casos a pelo menos 50 milhas náuticas da terra mais próxima e em águas com pelo menos 200 metros de profundidade.

- Estes parâmetros foram implementados, pois na região costeira a profundidade é reduzida. Caso o navio despeje a água de lastro dentro das 200 milhas estará aumentado a probabilidade de uma bioinvasão. 
A importância da implementação destas regras é impedir que o despejo ocorra dentro das áreas mostradas por Miller et al. (2005). Os autores analisaram 53.503 relatórios de água de lastro entregues à Guarda Costeira Americana (USCG) no período de 2004 e 2005, para identificar os pontos de coleta e despejo de água de lastro no país. A Figura 35 mostra o resultado da análise, os pontos amarelos representam os navios que despejam fora das 200 milhas e os pontos vermelhos na área restrita. A conclusão foi que cerca de 18.145 tanques despejaram água de lastro dentro das milhas náuticas.

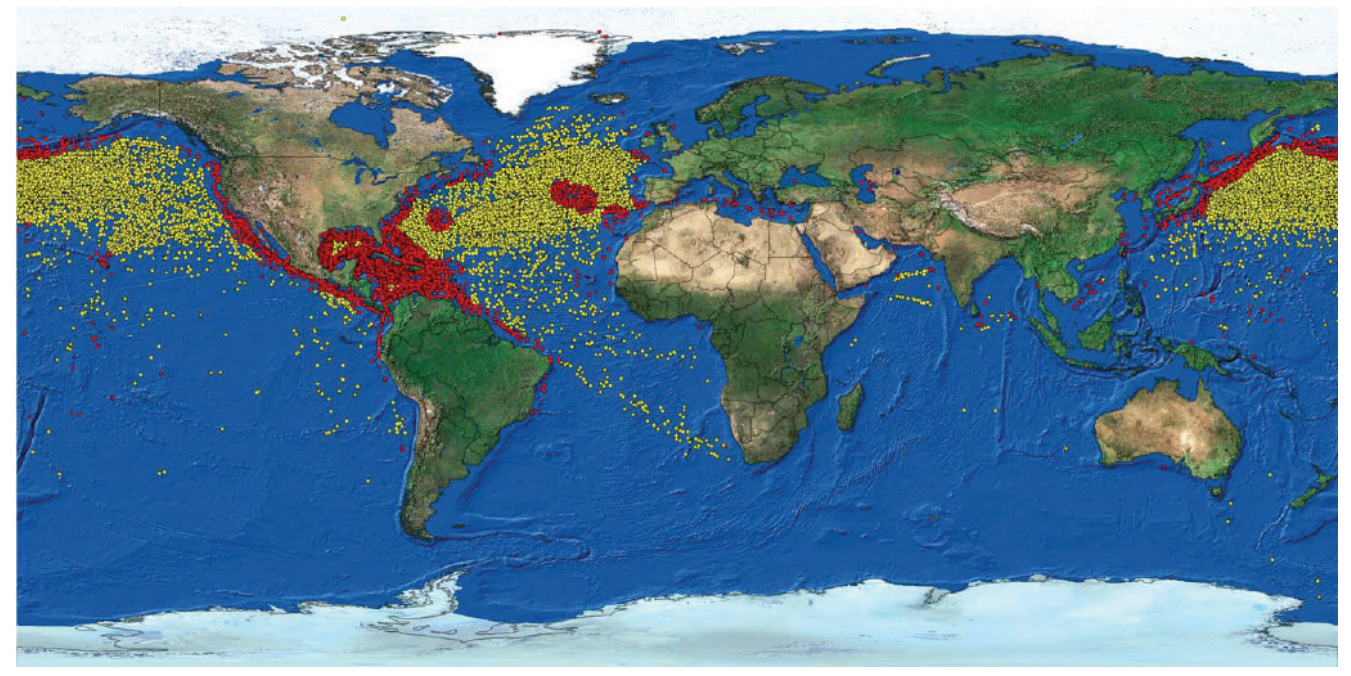

Figura 35 Pontos de descarga de água de lastro dos navios que operaram em águas americanas no período de 2004 e 2005

Fonte: Miller et al. (2005)

Isso mostra a necessidade da ratificação da BWMC, para que todos os países sigam as diretrizes e programas de monitoramento impedindo que os navios deslastrem fora da área indicada pela BWMC.

Mesmo antes da consolidação da BWMC, muitos países criaram seus próprios mecanismos de controle pautados nas recomendações da IMO, conforme mostrado a seguir.

Ações para controlar as espécies invasoras estão sendo desenvolvidas por nações individualmente sob os auspícios da Organização Marítima Internacional. A seguir apresentam-se as políticas de algumas nações.

\section{A.2) Esforços individuais das nações}

Embora a IMO, por uma questão de soberania, tenha sido incumbida de tomar as iniciativas de prevenção e controle da bioinvasão por meio da água de lastro, vários países ao longo do tempo desenvolveram suas próprias políticas 
para tratar o problema. Obviamente, que tais medidas estão em consonância com o que foi preconizado pela IMO. A seguir são apresentadas as principais iniciativas adotadas por algumas nações.

\section{A.2.1) Nova Zelândia}

Na Nova Zelândia estima-se que sejam lançados cerca de 70 milhões de $\mathrm{m}^{3}$ de água de lastro por ano (MS MINTON et al., 2005). Em 1989, o governo, em conjunto com a Austrália, criou um grupo de trabalho para desenvolver uma estratégia com vista a minimizar o risco de introdução de espécies exóticas oriundas da água de lastro.

Em 1992, em função das ações da IMO, a Nova Zelândia estabeleceu diretrizes voluntárias para serem adotadas pelos armadores. Em 1993, a autoridade reguladora estabeleceu o Biosecurity Act, que compreende uma ação para o controle e prevenção da introdução não intencional de espécies invasoras de qualquer fonte, fornecendo padrões de importação, controlando o movimento do navio e a entrada em quarentena. $\mathrm{O}$ sistema de quarentena é mais aplicado para navios que transportem água de áreas com alto risco de contaminação, como por exemplo, a China. Além disso, foi criada uma fundação para pesquisa e disseminação das informações nos mesmos moldes da Agência Americana National Invasive Species - NIS (GLOBALLAST, 2003).

Atualmente, a legislação vigente no país é a Import Healt Stander for Ships Ballast Water from All Countries - IHSSBWAC de 1998. Ela estabelece todos os procedimentos operacionais e legais que os navios estão sujeitos para adentrar nas águas da Nova Zelândia. Antes de um navio chegar ao porto, deve enviar ao Ministério da Agricultura e Serviço de Quarentena de Silvicultura uma solicitação de entrada junto com um formulário sobre as condições de lastro. Todos os navios que desejarem despejar água de lastro no país devem preencher e enviar o formulário "Ballast Water Report Form" completo, indicando o conteúdo dos tanques de lastros antes da descarga ocorrer. $\mathrm{O}$ inspetor responsável examina o documento e envia uma equipe de inspeção a bordo do navio para autorizar seu deslastro. Para que o navio possa deslastrar, deve atender um dos três critérios:

1. Demonstrar que água foi trocada na rota ou que os tanques contenham água doce.

2. Demonstrar que a água de lastro foi tratada usando uma unidade de tratamento a bordo aprovada pela IMO.

3. Garantir que a descarga da água será realizada em uma área ou uma unidade de recepção na costa.

Com a entrada em vigor da BWM Convention este país adotou a possibilidade dos navios realizarem a troca oceânica da água de lastro, bem como, a utiliza- 
ção de um BWMS a bordo. Deste modo, com as novas regras os países estão se adequando a nova realidade de gerenciar a água de lastro dos navios.

\section{A.2.2) Estados Unidos}

Após a descoberta do mexilhão zebra nos Estados Unidos, em 1986, o país intensificou seus esforços para combater as espécies invasoras. Em 1990, foi adotado o The Nonindigenous Aquatic Nuisance Prevention and Control Act (NANPCA), com um conjunto de diretrizes voluntárias para o gerenciamento da água de lastro nos navios que entrassem nos Grandes Lagos vindo das U.S. EEZ (United State Exclusive Economic Zone). Estes requisitos tornaram-se obrigatórios em 1993; foi estabelecido que navios que não obedecessem aos requisitos impostos pela USCG pagariam multas que variavam de US\$250.000,00 (individual) até US\$ 500.000,00 por dia, podendo ainda cumprir 12 anos de prisão (ENVIRONMENTAL PROTECTION AGENCY - EPA, 2008).

Em 1996, a NIS estabeleceu um Programa de Gerenciamento da Água de Lastro para a USCG. Em função disto foi publicada a Lei Federal 104-332, Aquatic Nuisance Prevention and Control16 U.S.C.A - Chapter 67, sobre a questão do gerenciamento da água de lastro.

Em 1999, a USCG implementou um programa em âmbito nacional, o National Ballast Survey (NABS), para mensurar o despejo de água de lastro oriunda dos navios mercantes que chegaram nos portos americanos de outras EEZ.

No ano de 2001, foi proposto no senado americano o Great Lakes Ecology Act. Esta foi uma proposta para desenvolver regulamentos mais rígidos para operação de navios nos Grandes Lagos. Além disso, foi criado pela USCG e pelo Departamento de Defesa, um programa especial, em conjunto com a IMO, para implementar novos programas de gerenciamento da água de lastro nos Estados Unidos.

Em 2004, o programa NABS foi estendido para incluir todos os navios comerciais com destino a qualquer porto dos EUA. O NABS foi projetado explicitamente para criar um banco de dados nacional de água de lastro.

Todos os navios com água de lastro nos EUA devem atender os requisitos relativos à descarga de água de lastro. Além disso, todo navio deve treinar pessoas sobre os procedimentos de gerenciamento de água de lastro e sedimentos. Devem atender também os critérios estabelecidos pela IMO, bem como, em alguns casos, só poderão ser autorizadas descargas pelo capitão dos portos da USCG. Os formulários de água de lastro devem ser entregues pelo navio 24 horas antes da chegada a qualquer porto americano.

Existem requisitos que são estabelecidos pelos Estados, tais como Califórnia, Washington, Oregon e Oakland. Ducan (2007) explica que na Califórnia, além dos navios cumprirem os procedimentos estabelecidos pela IMO, tanto para via- 
gens de longo curso quanto para cabotagem, eles têm que manter o plano de gerenciamento de água de lastro e pagar uma taxa de verificação no primeiro porto de parada. O mesmo se aplica para os outros estados. No final de 2008, foi aprovada pelo congresso uma lei que permite aos estados legislarem sobre os requisitos necessários para os navios despejarem a água de lastro em sua jurisprudência.

Em Junho de 2009, o comandante juntamente com o imediato filipino e o engenheiro chefe do navio grego $\mathrm{M} / \mathrm{V}$ Theotokos confessaram ter violado a lei antipoluição americana, pelo fato de terem despejado água de lastro contaminada na costa americana. A infração foi descoberta durante a vistoria da USCG, quando se aproximava de Nova Orleãs, em setembro de 2008. Segundo a ÁGUA DE LASTRO BRASIL (2009) foram julgados a empresa e a tripulação. O comandante e o imediato foram julgados em outubro de 2009. O restante da tripulação e a empresa foram julgados em dezembro de 2009. A Corte Americana proferiu as seguintes sentenças:

- O comandante do navio foi condenado a dez meses de confinamento, uma multa de US\$ 4.000,00 e uma proibição de três anos de entrar e acessar as águas territoriais americanas, por seu papel na obstrução da justiça, bem como as violações de leis ambientais e de segurança do navio..O chefe do navio de máquinas do Charles P. Posas, em outubro, foi condenado à liberdade condicional e uma proibição de acesso por três anos no país. Charles apresentou uma declaração falsa no livro de registro de água de lastro.

- Em cinco de novembro de 2009, o engenheiro-chefe, Georgios Stamou, foi condenado a pagar uma multa de US\$ 15.000 e um mandato de prisão preventiva, incluindo a proibição de cinco anos de acesso aos EUA, após se declarar culpado de um crime violação da lei de prevenção da poluição por navios e uma violação criminal por fazer uma declaração falsa.

- Aos outros nove ex-membros da tripulação foram concedidos um valor de US\$ 540.000,00 por terem contribuído com a investigação e indicado os culpados pela infração.

- A empresa Polembros Shipping gestora do navio foi condenada a pagar uma multa de US\$ 2,7 milhões e um pagamento adicional de US\$ 100.000,00 para Smithsonian Environmental Research Center, além de três anos de serviços comunitários. Essa foi a condição para que os seus dirigentes ficassem em liberdade condicional. Além disso, todos os outros navios da empresa ficaram impedidos de operar em águas americanas por três anos.

Entre os anos de 2010 a 2016 as discussões sobre água de lastro neste país tiveram fortes repercussões. Isso devido ao fato do Estado da Califórnia terem 
estabelecido critérios mais rigorosos para homologar sistemas de água de lastro em relação a IMO - D2.

Os critérios preconizados pela Califórnia estão apresentados na Tabela 7.

Tabela 7 Indicadores de performance para sistema de água de lastro exigidos pela Califórnia

\begin{tabular}{|c|c|c|}
\hline Organism Size Class & California & IMO Regulation D-2 \\
\hline $\begin{array}{l}\text { Organisms greater than } 50 \mu \mathrm{m} \\
\text { in minimum dimension }\end{array}$ & $\begin{array}{c}\text { No detectable living } \\
\text { organisms }\end{array}$ & $\begin{array}{l}<10 \text { viable organisms per } \\
\text { cubic meter }\end{array}$ \\
\hline $\begin{array}{l}\text { Organisms } 10-50 \mu \mathrm{m} \text { in } \\
\text { minimum dimension }\end{array}$ & $\begin{array}{l}<0.01 \text { living organisms } \\
\text { per ml }\end{array}$ & $\begin{array}{l}<10 \text { viable organisms per } \\
\mathrm{ml}\end{array}$ \\
\hline $\begin{array}{l}\text { Living organisms less than } 10 \\
\mu \mathrm{m} \text { in minimum dimension }\end{array}$ & $\begin{array}{l}<10^{3} \text { bacteria } / 100 \mathrm{ml} \\
<10^{4} \text { viruses } / 100 \mathrm{ml}\end{array}$ & \\
\hline Escherichia coli & $<126 \mathrm{cfu} / 100 \mathrm{ml}$ & $<250 \mathrm{cfu} / 100 \mathrm{ml}$ \\
\hline Intestinal enterococci & $<33 \mathrm{cfu} / 100 \mathrm{ml}$ & $<100 \mathrm{cfu} / 100 \mathrm{ml}$ \\
\hline $\begin{array}{l}\text { Toxicogenic Vibrio cholerae } \\
\text { (01 \& 0139) }\end{array}$ & $\begin{array}{l}<1 \mathrm{cfu} / 100 \mathrm{ml} \text { or } \\
<1 \mathrm{cfu} / \mathrm{gram} \text { wet weight } \\
\text { zoological samples }\end{array}$ & $\begin{array}{l}<1 \mathrm{cfu} / 100 \mathrm{ml} \text { or } \\
<1 \mathrm{cfu} / \mathrm{gram} \text { wet weight } \\
\quad \text { zooplankton samples }\end{array}$ \\
\hline
\end{tabular}

Fonte: Dobrosky, N. (2011) - Implementation of California's Performance Standards for the Discharge of Ballast Walter

Como podemos observar os critérios exigidos inicialmente propostos são pelo menos 100 vezes mais restritivos para organismos maiores de $50 \mu \mathrm{m}$ e 1.000 vezes para organismos na faixa de 10-50 $\mu \mathrm{m}$. Além disso, os indicadores relacionados com a presença de organismos vivos, bem como, bactérias também apresentam-se mais restritivos. No entanto, a partir de 24 de Julho de 2017, o Estado da Califórnia passou a adotar como critério os mesmos estabelecidos pela USCG, conforme apresentado no http://www.slc.ca.gov/Programs/MISP/USCGTALetterFinal.pdf.

O procedimento para aprovação dos sistemas pela pode ser encontrado no Legal Information Institute LII (www.law.cornell.edu) - código 162.060-10 Approval procedures.

Segundo CALIFORNIA STATE LANDS COMMISSION (2017) os padrões de desempenho de descarga de água de lastro provisórios da Califórnia estão programados para serem implementados considerando os seguintes marcos:

- Novo navio: em ou após 1 de janeiro de 2020 para navios recentemente construídos.

- Navio existente: a partir da primeira docagem programada a partir de $1^{\circ}$ de janeiro de 2020. 
Os sistemas que foram aprovados pela USCG estão apresentados a seguir.

Tabela 8 Sistemas aprovados pela Guarda Costeira até dezembro de 2017

\begin{tabular}{|c|c|c|c|}
\hline$\frac{\text { APPROVAL }}{\underline{\text { NUMBER }}}$ & MANUFACTURER & $\begin{array}{l}\text { APPROVAL } \\
\text { STATUS }\end{array}$ & ITEM DESCRIPTION \\
\hline$\underline{162.060 / 1 / 1}$ & Optimarin AS & APPROVED & Optimarin OBS/OBS Ex \\
\hline $162.060 / 2 / 2$ & Alfa Laval Tumba AB & APPROVED & $\begin{array}{l}\text { Alfa Laval PureBallast } 3 \text { Capacities: } 85 \text { - } \\
3000 \text { m3/h }\end{array}$ \\
\hline $162.060 / 3 / 3$ & $\underline{\text { TeamTec OceanSaver AS }}$ & APPROVED & $\begin{array}{l}\text { OceanSaver BWTS MKII Capacities: 200- } \\
7200 \text { m3/h (Models and operational ranges } \\
\text { shall be in accordance with the Range Ta- } \\
\text { ble provided in the OceanSaver Operation, } \\
\text { Maintenance, and Safety Manual) }\end{array}$ \\
\hline $162.060 / 4 / 0$ & $\begin{array}{l}\text { Sunrui Marine Environment } \\
\text { Engineering Co., Ltd }\end{array}$ & APPROVED & $\begin{array}{l}\text { SUNRUI BalClor Maximum Treatment Ra- } \\
\text { ted Capacities: 170/350/600/1200/1700 } \\
\text { /2200/2800/3200/3800/4300/5500/630 } \\
\text { 0/7300/8500 m3/h }\end{array}$ \\
\hline $162.060 / 5 / 0$ & Ecochlor, Inc. & APPROVED & $\begin{array}{l}\text { Ecochlor BWTS Capacities: 500/ } \\
\text { 1300/3500/6900/12200/16200 m3/h }\end{array}$ \\
\hline $162.060 / 6 / 0$ & $\begin{array}{l}\text { ERMA FIRST ESK Enginee- } \\
\text { ring Solutions S.A. }\end{array}$ & APPROVED & $\begin{array}{l}\text { ERMA FIRST BWTS FIT Capacities: 90/140/ } \\
\text { 200/300/515/600/800/1200/1250/1600 } \\
/ 2300 / 2500 / 3740 \mathrm{m3} / \mathrm{h}\end{array}$ \\
\hline
\end{tabular}

Fonte: https://cgmix.uscg.mil/Equipment/EquipmentSearch.aspx

Cabe frisar que existem pelo menos 101 fabricantes apresentaram desde abril de 2013 sistemas de tratamento de água de lastro para serem analisados pela USCG. Isso mostra uma ideia do mercado de tratamento de água de lastro previsto pelos fabricantes internacionais.

\section{A.2.3) Austrália}

A Austrália foi um dos primeiros países a ser signatário da IMO. É um país que tem um ecossistema marinho muito frágil com importantes corais e recifes com espécies raras. Além disso, o país dispõe de uma grande atividade pesqueira. A entrada de espécies invasoras tem comprometido todos os ecossistemas locais, afetando a pesca e a saúde humana. Neste sentido, em 1991, a Australia's Ballast Water Management Strategy detalhou um plano para o controle da água de lastro e de incrustações dos cascos. 
O país implementou em 1994 um plano nacional para lidar com o problema, incluindo suporte para pesquisa e técnicas de gerenciamento. Em adição, foi criado um Sistema de Suporte a Decisão - DSS - para determinar os navios vindos de áreas de alto risco, assim como identificá-los e inspecioná-los. O Ballast Water Research Development Levy foi implantado para dar suporte a estas atividades. A legislação vigente é a Quarantine Regulations criada em 2000, uma implementação do Quarantine Act, 1908.

O Quarantine Act, 1908 define água de lastro como "mercadoria"; deste modo, pessoas não podem remover mercadorias (incluindo água de lastro) de um navio ou instalação quando ele estiver em quarentena. É proibida a descarga sem permissão. Entre 12 e 48 horas antes da chegada de um navio no país, deve ser enviado o formulário de água de lastro para a Australian Quarantine Inspection Service, ou seja, um relatório de pré-chegada que detalha todas as questões para indicar se um navio deve ficar ou não em quarentena.

O navio é monitorado através do DSS via internet, Inmarsat-C ou através do agente de navegação que informa o último porto de parada, cinco dias antes da chegada na Austrália. A informação é analisada usando um software que associa o risco biológico, tanque por tanque. Para os navios, então, é dado um Risk Assessment Number (RAN) que é inserido nos arquivos do Quarantine Pré Arrival Report-QPAR para uso dos inspetores. Este sistema é avaliado pela internet no site (http://www.aqis.gov.au/shipping).

Além disso, os formulários devem ser mantidos a bordo do navio por dois anos. O navio pode optar pelos seguintes métodos de gerenciamento da água de lastro:

1. Os três métodos propostos pela IMO (troca oceânica, diluição e sequencial);

2. Análises do DSS que caracteriza os navios com baixo risco;

3. Transferência de tanque para tanque de alto risco para evitar descargas nas águas australianas;

4. Outros tipos de tratamentos poderão ser avaliados caso a caso.

Cabe salientar que é proibido descarregar sedimentos. Nestes casos, eles devem ser descartados em unidade apropriada em terra. Além disso, os navios devem fornecer acesso seguro para inspeções nos tanques de lastro. Os inspetores estão autorizados a conduzir processos específicos de verificação para navios que contenham pestes, enfermidades trazidas na água de lastro. A verificação do livro de registro dura aproximadamente 30 minutos e em casos de violações e entregas de documentos falsos, pode gerar cerca de um ano de prisão, mais multa.

Em julho de 2017, foi realizado uma atualização Ballast Water Management (BWM) do país. Neste são apresentados elementos relativos aos BWMS a bordo 
dos navios. Todos os navios que tenham estes sistemas abordo deverão apresentar o Type Approval Certificate (Certificado de aprovação) relativo especificamente ao BWMS. Além disso, foram estabelecidas as datas para a instalação de BWMS a bordo dos navios, conforme a data de entrada em vigor da BWMC.

\section{A.2.4) Canadá}

O Canadá, em 1998, apresentou o relatório de um estudo para a IMO intitulado "The Presence and Implication of Foreign Organisms in Ship Ballast Water Discharged in the Great Lakes" ao MEPC. Como no caso dos Estados Unidos, o Canadá foi fortemente atingido pelo impacto da água de lastro com a introdução de espécies não nativas de mexilhões na Baia de St Lawrence e nos Grandes Lagos.

A Shipping Federation of Canadá, uma associação industrial, foi a primeira a encorajar uma ação de troca de água de lastro para prevenir a invasão de espécies exóticas no país em meados de 1988. Em 1989, a Voluntary Guidelines for Control of Ballast Water Discharges from Ships Proceeding to the St. Lawrence River and Great Lakes foi criada pela Guarda Costeira Canadense. As diretrizes estabelecidas contemplavam a criação de uma zona de descarga de água de lastro no Canadá, diferentemente do que acontece em outros países. Entretanto, no que diz respeito aos investimentos na questão da água de lastro, o Canadá não apresenta grandes esforços como Estados Unidos e Austrália.

Todos os navios que adentrarem no país devem seguir as normas impostas pela IMO. Em casos de infração, a penalidade é de CND\$20.000,00 e em caso de reincidência CND\$50.000,00, mais um ano de prisão.

Em dezembro de 2017 também foram realizadas alterações nas regras para despejo de água de lastro no país. Estas modificações consideram a utilização de BWMS a bordo dos navios, como alternativa para gerenciamento. Contudo, mantem-se a possibilidade de troca oceânica da água de lastro, bem como, a manutenção dos registros de ocorrência e a proposição de medidas alternativas em caso de impedimento da operação de deslastro. Maiores informações podem ser obtidas pelo site: http://laws-lois.justice.gc.ca/PDF/SOR-2011-237.pdf.

\section{A.2.4) Brasil}

No caso do Brasil, antes mesmo do início do programa Globallast, o presidente da república sancionou as leis n. 9605/1998 e n. 9.966/2000, em 1998 e 2000 respectivamente, sendo a primeira conhecida como Lei de Crimes Ambientais e a segunda conhecida como Lei do Óleo. Ambas as leis dispõem sobre as questões ambientais, sendo que Lei n. 9.966/2000 dispõe mais especificamente sobre a prevenção, o controle e a fiscalização da poluição causada por lançamento de óleo e outras substâncias nocivas ou perigosas em águas sob jurisdição na- 
cional e dá outras providências. Estabelece a Lei: "os princípios básicos a serem obedecidos na movimentação de óleo e outras substâncias nocivas ou perigosas em portos organizados, instalações portuárias, plataformas e navios em águas sob jurisdição nacional".

Além disso, determina que "É proibida a descarga, em águas sob jurisdição nacional, de substâncias nocivas ou perigosas classificadas na categoria "A", definida no art. $4^{\circ}$ desta Lei, inclusive aquelas provisoriamente classificadas como tal, além de água de lastro, resíduos de lavagem de tanques ou outras misturas que contenham tais substâncias."

A Lei determina também que "Todo porto organizado, instalação portuária e plataforma, bem como suas instalações de apoio, disporá obrigatoriamente de instalações ou meios adequados para o recebimento e tratamento dos diversos tipos de resíduos e para o combate da poluição, observadas as normas e critérios estabelecidos pelo órgão ambiental competente".

A Lei também esclarece que: "a definição das características das instalações e meios destinados ao recebimento e tratamento de resíduos e ao combate da poluição será feita mediante estudo técnico, que deverá estabelecer, no mínimo:

I - as dimensões das instalações;

II - a localização apropriada das instalações;

III - a capacidade das instalações de recebimento e tratamento dos diversos tipos de resíduos, padrões de qualidade e locais de descarga de seus efluentes;

$I V$ - os parâmetros e a metodologia de controle operacional;

$V$ - a quantidade e o tipo de equipamentos, materiais e meios de transporte destinados a atender situações emergenciais de poluição;

$V I$ - a quantidade e a qualificação do pessoal a ser empregado;

VII - o cronograma de implantação e o início de operação das instalações".

No que tange à responsabilidade dos portos e armadores a lei estabelece "as circunstâncias em que a descarga, em águas sob jurisdição nacional, de óleo e substâncias nocivas ou perigosas, ou misturas que os contenham, de água de lastro e de outros resíduos poluentes for autorizada não desobrigam o responsável de reparar os danos causados ao meio ambiente e de indenizar as atividades econômicas e o patrimônio público e privado pelos prejuízos decorrentes dessa descarga".

Em relação às sanções, "respondem pelas infrações previstas neste artigo, na medida de sua ação ou omissão:

I - o proprietário do navio, pessoa física ou jurídica, ou quem legalmente o represente; 
II - o armador ou operador do navio, caso este não esteja sendo armado ou operado pelo proprietário;

III - o concessionário ou a empresa autorizada a exercer atividades pertinentes à indústria do petróleo;

IV - o comandante ou tripulante do navio;

$V$ - a pessoa física ou jurídica, de direito público ou privado, que legalmente represente o porto organizado, a instalação portuária, a plataforma e suas instalações de apoio, o estaleiro, a marina, o clube náutico ou instalação similar;

VI - o proprietário da carga.

$\int 2^{\circ} \mathrm{O}$ valor da multa de que trata este artigo será fixado no regulamento desta Lei, sendo o mínimo de $R \$ 7.000,00$ (sete mil reais) e o máximo de $R \$ 50.000 .000,00$ (cinquenta milhões de reais)”.

Embora, existam todos os procedimentos estabelecidos, durante a investigação bibliográfica, seminários, em fontes do governo e contatos com empresas de navegação e gestores portuários, não foram encontrados registros ou relatos de aplicação de multas por despejo de água de lastro no Brasil. Embora as infrações tenham ocorrido conforme apresenta (LEAL NETO, 2007). Cabe salientar, que existe uma discussão sobre a interpretação da lei no tocante a água de lastro, pois a lei sugere que seja a água misturada com óleo, contudo, a Lei n. 9966/00 coloca claramente "água de lastro" sem fazer distinção à água misturada com óleo ou não, então deve ser tratada a água de lastro despejada nos portos.

Neste contexto, para estabelecer os critérios para o gerenciamento da água de lastro, surge a primeira regulamentação nacional para lidar especificamente com a questão da água de lastro, denominada como NORMAM 20, que entrou vigor em 15 de outubro de 2005. A norma estabelece que todos os navios devem realizar a troca oceânica 200 milhas antes de entrar em um porto brasileiro, seguindo os mesmos parâmetros estabelecidos pela BWMC.

No entanto, a NORMAM 20/2005 estabelecia parâmetros diferenciados para a operação na região amazônica: navios oriundos de viagens internacionais devem realizar duas trocas de água de lastro. Isto se deve às características do local, que apresenta trechos com ecossistema bastante frágil, e também porque ocorre nestas regiões, o deságue dos rios no mar, o que pode gerar uma similaridade ambiental, devido à menor salinidade da água nestes trechos.

Assim, para navios que adentrassem o rio Amazonas, a primeira troca deveria ser realizada nos padrões da IMO, a segunda deveria ser realizada em Macapá, em que a água dos tanques devem ser recicladas apenas uma vez. Os navios que entram pelo Rio Pará, devem fazer a troca a 70 milhas da costa, entre Salinópolis e a Ilha do Mosqueiro. 
O relatório de água de lastro deveria ser enviado para as autoridades 24 horas antes de o navio chegar ao porto brasileiro. Entretanto, navios de guerra nacionais e estrangeiros, navios supply boat, barcos de pequeno porte e navios com lastro segregado são excluídos desta regulação. No entanto, a revisão da NORMAM 20/2014 retirou a obrigatoriedade da segunda troca da água de lastro, bem como, permitiu que os formulários fossem entregues durante o processo de atracação.

Atualmente, já está sendo aceito certificados relativos aos sistemas de tratamento de água de lastro a bordo que sejam homologados pelos órgãos internacionais. Neste caso, os navios não precisam realizar troca da água de lastro. Com a ratificação da BWM a tendência é que nos próximos anos grande parte dos navios tenham sistemas de tratamento a bordo, sendo realizada a troca da água de lastro somente em condições extremas.

Além das ações do governo, surgem ações isoladas de universidades e organizações não governamentais buscando avaliar os impactos causados pela água de lastro. Como o assunto ainda não tem uma questão fechada, existe sempre a necessidade de estudos e discussões continuas sobre o assunto.

\section{A.3) Competência brasileira}

A responsabilidade legal pelo controle e preservação do meio ambiente aquático é atribuição dos seguintes órgãos: Marinha do Brasil, Ministério dos Transportes, Ministério do Meio Ambiente e Ministério da Saúde pela Anvisa.

A Marinha do Brasil, como Autoridade Marítima, é uma das instituições brasileiras responsáveis, entre outras, pela prevenção e controle da poluição marinha gerada por navios. Apesar da água de lastro não estar relacionada a casos típicos de poluição, como óleo, lixo, produtos químicos e esgoto urbano, a introdução de espécies exóticas tem sido assunto discutido no âmbito da responsabilidade da Autoridade Marítima. A Marinha do Brasil também está vinculada a três instituições muito envolvidas com esse assunto: a Comissão Coordenadora dos Assuntos da IMO (CCA-IMO), a Comissão Interministerial para os Recursos do Mar (CIRM), ambas com suas Secretarias estabelecidas na Marinha, e a Representação Permanente do Brasil na IMO (RPBIMO).

O Ministério do Meio Ambiente (MMA) além de responsável, entre outros, pela política nacional do meio ambiente e dos recursos hídricos; pela política de preservação, conservação e utilização sustentável de ecossistemas, e biodiversidade e florestas e pela proposição de estratégias, mecanismos e instrumentos econômicos e sociais para a melhoria da qualidade ambiental e o uso sustentável dos recursos naturais, tem em sua estrutura o Instituto Brasileiro do Meio Ambiente e dos Recursos Naturais Renováveis - IBAMA, responsável pelo controle da poluição em águas marítimas. 
O Ministério do Meio Ambiente também exerce a Secretaria-Executiva do Conselho Nacional do Meio Ambiente (CONAMA), órgão responsável pelo estabelecimento, privativamente, de normas e padrões nacionais de controle da poluição causada por embarcações, mediante audiência dos Ministérios competentes. O MMA, o IBAMA, o CONAMA fazem parte do Sistema Nacional do Meio Ambiente (SISNAMA).

O Ministério da Saúde é responsável por lidar com saúde pública, e, em particular, quarentena e fiscalização sanitária (controle de fronteiras) através da Agência Nacional de Vigilância Sanitária (ANVISA). Sob a legislação brasileira, assuntos de saúde não se restringem à saúde humana.

A ANVISA também é um ator extremamente importante na gestão da água de lastro. A IMO permite que cada país tenha sua legislação especifica para tratar o problema da água de lastro. Deste modo, ela define o Estado do Porto, ou seja, a entidade legalmente reconhecida que define as normas e formas de controle para os navios que operam nos portos na sua jurisdição.

Nenhuma outra instituição está autorizada a legislar sobre a temática de água de lastro no Brasil.

\section{A.4) Projetos de Lei}

Ao longo dos anos foram criados diversos projetos leis para buscar inibir a contaminação por meio da água de lastro. Esses projetos foram encaminhados à Câmara e não tiveram aprovação. Para consultar estes projetos é necessário digitar no site a palavra-chave: água de lastro.

Alguns outros projetos foram propostos por Secretarias Estaduais do Meio Ambiente. O caso mais notório é do Maranhão. A SEMA criou a Portaria SEMA n. 18 DE 16/08/2016 que buscava implementar um processo de monitoramento da água de lastro por meio de uma empresa terceirizada que prestaria este serviço ao Estado. Contudo, a ação foi considerada inconstitucional, pois ultrapassava as competências do Estado que estava legislando sobre uma questão federal. Esta iniciativa sofreu uma forte resistência da comunidade marítima e portuária local.

Em outubro de 2016, a Companhia Docas do Rio de Janeiro também aprovou a INSTRUÇÃO NORMATIVA n. 53/2016 para Procedimento para credenciamento de empresas especializadas em implementação e administração de serviços técnicos de conformidade, monitoramento e efetivação (CME) da água de lastro e sedimentos provenientes de plataformas, navios e embarcações similares, nas áreas dos portos organizados da CDRJ. Em ambos os casos as ações não tiveram respaldo legal e até dezembro de 2017 não ocorreu nenhuma mudança na forma de fiscalização e verificação da água de lastro realizada pela Marinha do Brasil. 


\subsection{REFERÊNCIAS}

AGÊNCIA NACIONAL DE VIGILÂNCIA SANITÁRIA. Água de lastro. Projetos GGPAF. 2002-2003. Brasil.

ÁGUA DE LASTRO BRASIL. A água de lastro e os seus riscos ambientais. Disponível em: http://www.aguadelastrobrasil.org.br. Acessado em 05/07/2009. 2009.

CALIFORNIA STATE LANDS COMMISSION (2017). Disponível em: http://www.slc. ca.gov/Programs/MISP.html.

DUCAN, J. L. Ballast water: extremely convenient for the shipping industry but disastrous for coastal waters and environment: a study on the effect of ballast water on various coasts and the laws and regulations in place regarding ballast water. Institute of Marine and Environmental Law. Faculty of Law. University of Cape Town. Master Dissertation in Marine and Environmental Law. 2007.

EMMANUELA, K. T. The international convention for the control and management of ship's ballast water and sediments 2004: a critical appraisal. Institute of Marine and Environmental Law. Faculty of Law. University of Cape Town. Master Dissertation in Marine and Environmental Law. 2007.

ENVIRONMENTAL PROTECTION AGENCY - EPA, BALLAST WATER TREATMENT. 2008. Environmental Protection Association. Disponível em: http://yosemite. epa.gov/sab/sabproduct.nsf/DAE3502A9D618F11852577CE0060A774/\$File/Draft+On shore+Treatment+for+Subgroup+3.+Cohen.+10.28.2010.pdf.

GLOBALLAST WATER MANAGEMENT PROGRAMME. On guidelines and standards for ballast water sampling. Monograph. 2003.

HENRIQUE, M. M. Estudo do risco de introdução de espécies exóticas e agentes patogênicos através da água de lastro de navios cargueiros no Porto de Tubarão. Monografia. Pontifícia Universidade Católica de Minas Gerais. Instituto de Ensino Continuado. Curso de Especialização em Engenharia Ferroviária. 2006.

LEAL NETO, A. C. Identificando similaridades: uma aplicação para a avaliação de risco de água de lastro. Tese (Doutorado) apresentada à Universidade Federal do Rio de Janeiro em Ciências em Planejamento Energético. 2007.

MILLER, A. W.; G. M., Ruiz; K., Lion. Status and trends of ballast water management in the United States. Third biennial report of the National Ballast Information Clearinghouse (January 2004 to December 2005). Submitted to the United States Coast Guard 3.3 (2007): 1-62.

MINTON, M. S. et al. Reducing propagule supply and coastal invasions via ships: effects of emerging strategies. Research Communications. Front Ecol. Environ. 2005.

PEREIRA, N. N.; BRINATI, H.L. Estudo sobre tratamento de água de lastro. $22^{\circ}$ Congresso Nacional de Transportes Marítimos, Construção Naval e Offshore - Rio de Janeiro. RJ. Outubro de 2008.

PEREIRA, N. N.; CONTI, M. Técnicas para avaliação de um sistema de gerenciamento de água de lastro. Revista Fatecnologia. 2008. 